\title{
O drama do gênio na metafísica do belo de Schopenhauer: sua mais alta expressão no Torquato Tasso de Goethe
}

\author{
The genius' drama in the metaphysics of the schopenhauer's beautiful: his \\ highest expression in "Torquato Tasso" by Goethe
}

\author{
Iasmim Martins \\ Mestranda em Filosofia pela UFRRJ \\ E-mail: Iasmim.martins98@gmail.com
}

\begin{abstract}
Resumo: Para Schopenhauer, o que caracteriza o gênio é o excedente da faculdade de conhecer (genialidade) que lhe possibilita acesso imediato à Ideia por meio da contemplação intuitiva, enquanto puro sujeito do conhecimento. Todavia, esta mesma potencialidade amplifica a vontade do gênio, quando este retoma a condição de indivíduo. Segundo o filósofo, o excedente da faculdade de conhecer pode tomar duas orientações, excludentes entre si: a orientação objetiva, quando ele se torna livre da servidão da vontade, ou a orientação subjetiva, ocasião em que o excedente se coloca a serviço da vontade individual. Por conta dessas duas orientações do excedente, o gênio ora se abstém do sofrimento, ora sofre de maneira extremada. O presente artigo pretende apresentar a hipótese de que o gênio vivencia um drama existencial, que ultrapassa sobremodo o sofrimento natural inerente aos outros homens. Para tanto, objetiva-se recorrer à obra Torquato Tasso do Goethe, citada pelo próprio Schopenhauer.
\end{abstract}

Palavras-Chave: Gênio; Contemplação; Drama.

Abstract: To Schopenhauer, a genius is characterized by the surplus of the faculty of knowing, which allows these individuals to have immediate access to the Idea through the intuitive contemplation, while a pure being of the knowledge. However, this potentiality amplifies the genius' will, when the status of individual is retaken. According to the philosopher, the surplus of the faculty of knowing may take two guidances, which exclude themselves: the objective guidance, when one is freed from the bondage of the will, or the indirect guidance, occasion when the surplus is available to the individual guidance. As a consequence of the surplus, the genius either neglects suffering or suffers radically. This article intends to present the following hypothesis: the genius goes through existential drama that greatly surpasses the natural suffering inherent to other people. Thereunto, Torquato Tasso, Goethe's work, was utilized, since it has been mentioned by Schopenhauer

Keywords: Genius; Contemplation; Drama.

(...) Eu sinto em mim o borbulhar do gênio,

Vejo além um futuro radiante; Avante! - brada-me o talento n'alma E o eco ao longe me repete - avante!

Castro Alves Mocidade e Morte. 


\section{Considerações iniciais}

Pode-se considerar que a experiência estética ocupa um papel fundamental na filosofia de Schopenhauer, de modo que contemplar o belo pode vir a ser uma superação, ainda que momentânea, da vontade, portanto, da dor e do sofrimento inerentes à existência. Como confirma Safranski: "a contemplação do mundo tem de ser estética, porque está libertada dos impulsos da vontade ${ }^{1}$ ". Depois de ter tomado o mundo como Vontade (Wille) e como Representação (Vorstellung), Schopenhauer nos presenteia com sua metafísica do belo e, em meio ao caos e ao sofrimento que é já a própria vida, aparece a contemplação estética como fio de esperança na teoria do autor. Além disso, o conhecimento estético, que provém da intuição, é privilegiado por Schopenhauer em detrimento do conhecimento científico, que advém da abstração e da razão e que, por esse motivo, está submetido ao fio condutor do princípio de razão, não podendo, portanto, ser o meio pelo qual conhecemos a essência das coisas. Por conseguinte ele diz que "o modo de consideração que segue o princípio de razão é o racional, o único que vale e que auxilia na vida prática e na ciência", já o modo de conhecimento genial é "o modo apartado do conteúdo do princípio de razão"2. O primeiro é a maneira ordinária pela qual conhecemos as coisas e o segundo é a maneira pela qual se pode conhecer a essência das mesmas.

Para quem se debruça sobre a filosofia de Schopenhauer, cabe ter claro que ele não pretendia elaborar uma teoria estética ${ }^{3}$, mas fundar uma metafísica do belo, visto que sua preocupação concentrava-se na essência do belo, tanto no que diz respeito ao sujeito que possui a sensação do belo, quanto ao objeto que a ocasiona ${ }^{4}$. Em suas considerações sobre o belo, Schopenhauer afirma que este pode ser encontrado tanto nas obras de arte, quanto na natureza, à diferença de Hegel para o qual tratar da questão do belo é fazer "filosofia da bela arte", sendo o belo natural rebaixado 5 .

\footnotetext{
${ }^{1}$ SAFRANSKI, Rüdiger. Schopenhauer e os anos mais selvagens da filosofia. São Paulo: Geração Editorial, 2011, p. 399.

${ }^{2}$ SCHOPENHAUER, A. Metafísica do Belo, cap.5, p. 59.

3 "A estética ensina o caminho pelo qual o efeito do belo é atingido, dá regras às artes, segundo as quais elas devem criar o belo". SCHOPENHAUER. A. Metafísica do Belo, cap.1, p.24.

${ }^{4}$ Cf. SCHOPENHAUER. A. Metafísica do Belo, cap.1, p. 24.

${ }^{5}$ BARBOZA, Jair. Introdução. In: SCHOPENHAUER, A. Metafísica do Belo, p.14. 
Para Schopenhauer, os dois maiores filósofos do ocidente eram Platão e Kant; sendo assim, ele toma como base a teoria de ambos para fundamentar sua própria filosofia. Segundo Schopenhauer, o sentido íntimo das doutrinas de Kant e Platão, de alguma maneira, era o mesmo, pois ambos tomam o mundo visível como mero fenômeno, porém o oposto do fenômeno Kant denominou de coisa-em-si e Platão de Ideia. Apenas a estas esses filósofos conferem o ser verdadeiro, recusando as formas gerais do fenômeno ${ }^{6}$. Considerando que Schopenhauer toma a coisa-em-si kantiana como vontade e a partir disso torna-se o autor de uma metafísica imanente, de que modo entraria a Ideia platônica na filosofia do solitário de Frankfurt? Ela aparece justamente como objetidade adequada da vontade ${ }^{7}$ que constitui o em-si do mundo, sendo, portanto, o conceito central da metafísica do belo, visto que o conhecimento estético é sempre já conhecimento de Ideias. Como ressalta Clément Rosset: "Schopenhauer definiu por várias vezes a estética, e a arte em geral, como conhecimento das Ideias" ${ }^{\prime}$. Portanto, passaremos a tratar do conhecimento das Ideias para depois adentrarmos no conflito existencial do gênio, questão central desse artigo.

\section{Do conhecimento das Ideias}

Tendo em vista que na filosofia de Schopenhauer contemplar é conhecer, conhecer verdadeiramente o que é essencial, como poderíamos conhecer algo que é transitório? É por isso que ao contemplar entramos em contanto com a Ideia, pois só nela há a essência íntima dos objetos, já que ela não se transforma nem perece, portanto, é imutável e independente da existência temporal dos seres individuais. Por isso, é representação independente do princípio de razão e se constitui como objetidade adequada da vontade (adäquaten Objektität des Willens) ${ }^{9}$. Ambas não são a mesma coisa, mas estão intimamente conectadas. A Ideia é a vontade na medida em que esta se tornou objeto, contudo ainda não entrou no espaço, no tempo e na causalidade.

\footnotetext{
${ }^{6}$ SCHOPENHAUER. A. Metafísica do Belo, cap.2, p. 36.

${ }^{7}$ SCHOPENHAUER, A. WWV/MVR II, cap. XXX, P. 25.

${ }^{8}$ Cf. ROSSET, Clément. Écrits sur Schopenhauer. Paris: Presses Universitaires de France, 2001. p. 171. Tradução nossa.

${ }^{9}$ SCHOPENHAUER, A. WWV II /MVR II, cap. XXX, p. 25. 
No que diz respeito à fruição do belo, Schopenhauer ressalta que o prazer sentido na experiência estética é extremamente diferente dos outros prazeres, pois contemplar o belo nada tem a ver com a satisfação de uma vontade individual. A alegria que os indivíduos sentem com suas relações pessoais e por meio de fins alcançados nada tem a ver com a alegria com o belo, mas com o que lhes é útil, agradável. A alegria com o belo, no entanto, é da ordem do conhecimento, exclusivo e puro, sem que os objetos do conhecimento tenham relação com nossos fins pessoais. Portanto, a alegria com o belo é inteiramente desinteressada. $\mathrm{Na}$ filosofia de Schopenhauer, tal como na de Kant, belo é o que agrada, independente de todo interesse $^{10}$. No entanto, para Schopenhauer, o belo é de natureza objetiva, e não subjetiva, tendo, por sua vez, de ser belo independentemente da vontade ou do interesse dos indivíduos. Por esse motivo, ele pode ser encontrado nas Ideias e não nas formas gerais do fenômeno.

Segundo Schopenhauer, o conhecimento é sempre objetivo, isto é, não existe para tal ou qual indivíduo, mas para o sujeito em geral. Desse modo, o belo pode ser conhecido de acordo com a capacidade (Fähigkeit) que cada um possui para acessá$10^{11}$. Além disso, o modo de conhecimento estético não pode ser comunicado por doutrinas e conceitos ${ }^{12}$, mas apenas por obras de arte, não podendo ser conhecido de modo abstrato ${ }^{13}$, mas só intuitivamente. É através da intuição que chegamos a conhecer as Ideias, mas cabe a ressalva de que as Ideias não são objetos do pensamento (Gedankending), elas encontram-se no mundo intuitivo e são conhecidas pelo sujeito que as conhece por meio da contemplação. Como afirmamos anteriormente, o conhecimento existe para um sujeito em geral, então, para contemplar, é preciso que haja uma mudança prévia no sujeito, isto é, é preciso deixar de ser indivíduo, portador de vontade, para passar a ser puro sujeito que conhece, destituído de vontade. Só assim se chega a conhecer, verdadeiramente, as Ideias.

\footnotetext{
${ }^{10}$ Cf. KANT, Immanuel. Crítica da Faculdade do Juízo. Rio de Janeiro: Forense Universitária, 2010.

${ }^{11}$ Exceto o filisteu (homem sem necessidades espirituais). Desprovido de capacidade estética, sem ímpeto para a fruição estética. Cf. SCHOPENHAUER, A. Aforismos para a sabedoria de vida. cap. II, p. 46.

${ }^{12} \mathrm{O}$ caráter não conceitual do belo já aparece em Kant. Cf. KANT, Immanuel. Crítica da Faculdade do Juízo. Rio de Janeiro: Forense Universitária, 2010, p. 56.

${ }^{13}$ Para Schopenhauer, o conhecimento abstrato é de ordem científica, o conhecimento genial, isto é, artístico, é sempre intuitivo. Cf. SCHOPENHAUER, A. Metafísica do Belo, cap.7 "Oposição entre ciência e Arte", p. 59.
} 
Então, para haver contemplação, é preciso que haja uma transição do conhecimento comum, que concebe coisas isoladas, para o conhecimento da Ideia. Mas isso não ocorre sempre e, além disso, parece ocorrer de modo espontâneo. Quando contemplamos, é como se estivéssemos sob um estado de graça. A contemplação é sempre um perder-se no objeto, esquecer-se de si mesmo e permanecer serenamente na fruição do belo de maneira clara e objetiva. Schopenhauer diz:

Para conceber [Auffassun] uma Ideia [Idee] e permitir a sua entrada em nossa consciência, precisamos de uma mudança em nós mesmos, a qual pode ser tomada também, como um ato de autonegação [Akt der Selbstverläugnung]. Desse modo, consiste em que o conhecimento se afaste totalmente de nossa vontade e, assim, deixando totalmente fora de vista a promessa preciosa que lhe foi confiada, considere as coisas como se elas nunca pudessem, de nenhum modo, dizer respeito à vontade. Pois, só assim é que o conhecimento se torna espelho puro [reinen Spiegel] do ser objetivo das coisas. Um conhecimento assim tão condicionado deve ser o fundamento de toda genuína obra de arte, bem como a sua origem. A mudança no sujeito necessária para isso, apenas porque consiste na eliminação de todo querer, não pode prosseguir a partir da vontade e, portanto, não pode ser um ato arbitrário de vontade, ou, por outras palavras, não pode persistir em nós. ${ }^{14}$

Vimos que a essência do belo ocupa um papel fundamental na filosofia de Schopenhauer, de modo que tanto a contemplação de uma obra de arte quanto da natureza não requer aquele olhar afetado pelo querer de quem só apreende os objetos na medida em que estes tenham alguma relação com a sua vontade. Então, como seria possível contemplar o belo? Já sabemos que a contemplação só se da através da intuição, porém, como os homens podem chegar a intuir?

\section{O gênio e seu drama}

É possível contemplar/conhecer o belo através da faculdade conhecida como genialidade - capacidade que cada indivíduo possui em maior ou menor grau de intuir, de afastar-se do querer para conhecer verdadeiramente. Aquele que deixa de ser

\footnotetext{
${ }^{14}$ SCHOPENHAUER, A. WWV II /MVR II, cap. XXX, p. 19.
} 
indivíduo e torna-se puro sujeito do conhecimento, correlato da Ideia; que é capaz de uma contemplação objetiva, ao invés de se deixar levar pela exigência de sua vontade, ou seja, o sujeito que de modo objetivo apreende as Ideias, não se deixando levar pela mera aparência dos fenômenos perecíveis, Schopenhauer denomina gênio:

\begin{abstract}
Apenas pela pura contemplação a dissolver-se completamente no objeto é que as Ideias são apreendidas. A capacidade proeminente para esta é o gênio, somente do qual podem originar-se as obras de arte autênticas. Toda contemplação exige pura disposição objetiva, isto é, esquecimento completo da própria pessoa e de suas relações; por conseguinte, a genialidade nada é senão a objetividade mais perfeita, ou seja, orientação objetiva do espírito; em oposição à subjetiva, que vai de par com a própria pessoa, isto é, a Vontade ${ }^{15}$.
\end{abstract}

Gênio consistiria, então, na livre ação do intelecto, ou seja, um intelecto emancipado do serviço da vontade ${ }^{16}$. Através da intuição o gênio atinge alto grau de objetividade e passa a ser puro sujeito que conhece, apreendendo a essência mesma das coisas. Nessas ocasiões, deixa de ser meramente indivíduo. Schopenhauer, porém, adverte que mesmo os homens que não são gênios possuem a capacidade de contemplar. Em outras palavras, possuem a faculdade de genialidade em maior ou menor grau. Por isso, eles podem contemplar a natureza e as obras de arte produzidas pelo gênio.

No entanto, se o indivíduo comum possui também essa capacidade de contemplação, em que consistiria, então, a diferença entre ele e o indivíduo genial? Para Schopenhauer, ambos recebem as mesmas impressões do mundo externo ${ }^{17}$. Não obstante, o indivíduo genial é dotado de um excedente da faculdade de conhecimento ${ }^{18}$ que lhe possibilita destituir-se de sua vontade e objetivamente entrar em contato com a Ideia. Como afirma Schopenhauer, no parágrafo $§ 37$ de $O$ Mundo, "o gênio possui tão somente um grau mais elevado e uma duração mais prolongada daquele conhecimento, o que lhe permite conservar a clareza de consciência exigida para reproduzir numa obra

\footnotetext{
${ }^{15}$ Cf. SCHOPENHAUER, A. Metafísica do Belo,cap.6, p. 60-61.

${ }^{16}$ SCHOPENHAUER, A. WWV II /MVR II, cap. XXXI, p. 43.

${ }^{17}$ Idem, p. 68.

${ }^{18}$ Cabe ressaltar que esse excedente da faculdade de conhecimento nada tem a ver com a inteligência excepcional. A raiz do gênio está no modo intuitivo de concepção do mundo, ao contrário, os homens inteligentes concebem o mundo racionalmente e possuem apenas espírito, talento. Cf. Metafísica do Belo, cap.6, p. 69.
} 
intencional o assim conhecido" 19 . O que caracteriza o gênio é o modo intuitivo de conhecer o mundo ${ }^{20}$, isto é, o gênio percebe o mundo diferente dos demais; aquilo que por vezes está diante de todos e é ignorado é justamente o que o gênio apreende profundamente. "Ver o universal no particular é sempre precisamente a característica do gênio" 21 . Isto quer dizer que o objeto do gênio é a essência das coisas em geral, o que provém de sua capacidade de apreensão da totalidade completamente desvinculada de interesses egoísticos. Por isso, só o gênio produz a obra de arte autêntica ${ }^{22}$, pois é através dela que ele nos empresta a sua visão de mundo, como que emprestando seus olhos $^{23}$ para que os outros homens possam apreender as Ideias que foram apreendidas e expressas através de suas obras. O conhecimento genial é sempre conhecimento da essência das coisas, das Ideias, por essa razão o conhecimento genial é o único que auxilia na $\operatorname{arte}^{24}$.

Por possuir o excedente da faculdade de conhecimento, logo, o predomínio do conhecer sobre o querer, o gênio possui a vantagem de encontrar-se em paz muitas vezes e em estado de calma contemplação, ou, no momento de inspiração, quando ele está produzindo suas obras. Assim sendo, ele consegue se desatar por mais vezes da roda esmagadora do querer, o que faz com que ele tenha certa vantagem com relação aos outros homens, pois, livre da vontade, também se encontra livre do sofrimento, em alguns momentos, enquanto os outros continuam súditos do querer.

Outra vantagem do gênio é bastar-se a si mesmo de modo que ele não precisa se entregar a vulgaridade e a distrações banais tal como os homens em geral. Enquanto os homens comuns se consolam ou tentam afugentar seu tédio com companhia, trabalho, prazeres etc, o gênio, entretanto, por sua grandeza de espírito, encontra-se em paz consigo mesmo e desfruta da solidão e do ócio, como afirma Schopenhuaer nos Aforismos para a sabedoria de vida:

\footnotetext{
${ }^{19}$ SCHOPENHAUER, A. WWV I/MVR, I, § 37, p. 265.

${ }^{20} \mathrm{O}$ vigor da fantasia é também condição do gênio, mas genialidade e fantasia não são sinônimos. Nem todo mundo que possui a capacidade de fantasiar é gênio. Cf. SCHOPENHAUER, A. WWV I/MVR, I, $\S 36$, p. 255, 256.

${ }^{21}$ SCHOPENHAUER, A. WWV II /MVR II, cap. XXXI, p.35.

${ }^{22}$ SCHOPENHAUER, A. Metafísica do Belo, cap. 6, p. 61.

23 "Que ele possua tais olhos a desvelar-lhe o essencial das coisas, independente de suas relações, eis aí precisamente o dom do gênio. Cf. SCHOPENHAUER, A. WWV I/MVR, I, § 37, p. 265.

${ }^{24}$ SCHOPENHAUER, A. Metafísica do Belo, cap.5, p.59.
} 
(...) Somente para um homem dessa estirpe a ocupação imperturbada consigo mesmo, com seus pensamentos e suas obras é uma necessidade premente. A solidão para ele é bem-vinda, o ócio é o bem supremo e todo os resto é dispensável; caso exista, com frequência é apenas um fardo. Por conseguinte, somente de tal homem podemos dizer que seu centro gravitacional encontra-se nele mesmo ${ }^{25}$.

A respeito dos outros homens ele afirma: "O vazio de sua interioridade, a sensaboria de sua consciência, a pobreza de seu espírito os impele a procurar companhia"26. Contudo, esse poder de conhecimento do gênio também pode proporcionar-lhe outro tipo de vivência. Como nada é unilateral, a existência do gênio também possui mais de um lado. Lado esse que não é o da superação da dor, mas, pelo contrário, é a vivência e o mergulho profunda nela.

Se, por um lado, o excedente da faculdade de conhecimento representa para o gênio uma vantagem, pois o acesso ao belo o livra momentaneamente da vontade e do sofrimento dela decorrente, por outro pode significar uma desvantagem, à medida que esse mesmo excedente do conhecimento, quando se encontra submetido à orientação subjetiva do espírito, o torna excessivamente afetado pela vontade, isto é, faz com que ele confira a tudo o que existe uma dimensão extraordinária, inclusive àquilo que afeta diretamente sua sensibilidade e seu estado emocional ${ }^{27}$. Disso resulta que o homem genial vivencia as dores do mundo de uma forma extremada, diferentemente dos indivíduos comuns.

Isso faz com que o gênio sofra mais do que os outros homens, ou que o sofrimento dele ocorra de maneira completamente diferente, pois mesmo que esteja preso à sua individualidade e, portanto, ao seu querer, o que ele quer não é o mesmo que os outros homens querem, já que, para o filósofo em questão, o gênio procura incessantemente outros objetos, dignos de contemplação ${ }^{28}$. Mesmo que o gênio esteja na condição de indivíduo, parece-nos que tanto sua constituição quanto seu modo de perceber/vivenciar ${ }^{29}$ o mundo ainda são extremamente diferentes do

\footnotetext{
${ }^{25}$ SCHOPENHAUER, A. Aforismos para a sabedoria de vida, cap. II, p. 41.

${ }^{26}$ SCHOPENHAUER, A. Aforismos para a sabedoria de vida, cap. I, p. 13.

${ }^{27}$ SCHOPENHAUER, A. Metafísica do Belo, cap. I, p. 75.

${ }^{28}$ SCHOPENHAUER, A. Metafísica do Belo, cap.6, p. 63.

${ }^{29}$ Mesmo quando o indivíduo não está imerso no modo de conhecimento genial (tomado por um genius) seus méritos e suas carências não desaparecem por completo, mas são menos notados Cf. SCHOPENHAUER, A. Metafísica do Belo, cap.6, p.72.
} 
modo como os homens comuns percebem as coisas a sua volta. A respeito disso, Schopenhauer esclarece:

Há uma grande distância entre a racionalidade propriamente dita, o autocontrole seguro, a visão geral fechada, plena de segurança, a regularidade de comportamento que se encontram num homem comum racional, e o estado ora de absorção onírica, ora de excitação nervosa do homem genial. Mas se poderia dizer que aquela tranquilidade e segurança do homem comum é comparável à segurança com a qual um andarilho noturno segue com olhos fechados caminhos perigosos. O homem sem gênio conhece meramente as relações, ele adquire nestas uma visão geral plena de uma totalidade fechada; ao contrário, a essência que se exprime no fenômeno - as suas Ideias -, não a toma por verdadeira ${ }^{30}$.

Esse modo completamente diferente de considerar as coisas e até mesmo de estar no mundo é o que diferencia o gênio do homem comum. O homem comum não consegue contemplar de modo sereno e duradouro, ao contrário, ele direciona sua atenção para as coisas de acordo com sua vontade, ele busca sempre o conceito abstrato delas, por ser-lhe mais útil do que a intuição. Portanto, o homem comum se alegra mais facilmente com qualquer coisa, se dando por contente com o que the aparece e ignorando o que é essencial. O gênio, por sua vez, está entregue à consideração da essência íntima das coisas e, por essa razão, acaba por negligenciar as relações e sua própria vida.

Por um lado, o gênio possui a vantagem de ver o mundo mais belo e mais claro, pois a representação lhe aparece mais pura, isto é, menos turvada pela vontade; por outro lado, possui desvantagens, justamente por considerar a Ideia das coisas e ignorar o conhecimento preso ao princípio de razão ${ }^{31}$. Segundo Schopenhauer, essa negligência do gênio com relação ao princípio de razão faz com que cada disposição seja sobrecarregada e cada movimento se torne afeto, excedendo às medidas. Por isso, ele vai percorrendo o caminho e tornando claro como a aversão do gênio em seguir o

\footnotetext{
${ }^{30}$ SCHOPENHAUER, A. Metafísica do Belo, p. 64.

${ }^{31}$ Para Schopenhauer, o gênio negligencia as quatro figuras do princípio de razão suficiente: 1) princípio de razão do devir, que rege as representações empíricas, as intuições; 2) princípio de razão do conhecer, que rege as representações abstratas, os conceitos da razão; 3) princípio de razão do ser, que rege as representações a partir das formas puras da sensibilidade, o espaço e o tempo; e 4) princípio de razão do agir, que rege as ações a partir de motivos. Cf. CHEVITARESE, Leandro. A ética em Schopenhauer: que "liberdade nos resta" para a prática de vida? Tese de Doutorado. Pontifícia Universidade Católica do Rio de Janeiro, Rio de Janeiro, 2005.
} 
princípio de razão, no seu conhecer, conduz a certas carências. A primeira já aparece em referência ao princípio de razão do ser, como aversão à matemática, cuja consideração se atém as formas mais gerais do fenômeno (espaço e tempo), figuras do princípio de razão. O gênio considera justamente o conteúdo do fenômeno, a saber, a Ideia que nele se expressa. Além do mais, o procedimento lógico da matemática contraria o gênio, pois oferece simplesmente cadeias de conclusão conforme o princípio de razão do conhecer $^{32}$. Para o filósofo, matemáticos também possuem pouca receptividade para a fruição da $\operatorname{arte}^{33}$, embora possamos encontrar exceções em ambos os casos.

Outra característica marcante do gênio é a imprudência, ele se diferencia dos homens racionais prudentes e "sensatos" a sua volta justamente porque ele não possui certa concepção das relações conforme as leis de causalidade e motivação, essa concepção sagaz das relações que tornam alguém prudente ${ }^{34}$. Não obstante, a racionalidade é oposta a genialidade, uma não faz par com a outra, daí se segue que os indivíduos geniais são submetidos a afetos e paixões irracionais. Schopenhauer adverte que "o fundamento disso, todavia, não é a fraqueza da razão, mas em parte reside em que o indivíduo genial, nele mesmo, é um incomum fenômeno enérgico da vontade, a exteriorizar-se numa grande veemência de atos" ${ }^{, 3}$. Reside também no fato de que o conhecimento predominante no gênio é o conhecimento intuitivo sobre o abstrato. A impressão do conhecimento intuitivo é altamente enérgica e por isso ofusca os conceitos fazendo com que esses não guiem as ações do gênio. Portanto, essas ações são irracionais. Além disso, a percepção do presente que lhe é própria e seu modo singular de considerar as coisas faz com que ele seja tomado pelo irrefletido, pelo afeto, pela paixão.

Além disso, tomada a orientação subjetiva do espírito, o seu querer se torna afetado pelo seu poder brilhante de conhecimento, daí sua vontade é superexcitada e suas representações são excessivas, fazendo com que cada movimento se torne afeto, ultrapassando as medidas:

\footnotetext{
${ }^{32}$ SCHOPENHAUER, A. WWV I/MVR, I, §36, p. 259.

${ }^{33}$ SCHOPENHAUER, A. WWV I/MVR, I, §36, p. 258.

${ }^{34}$ SCHOPENHAUER, A. WWV I/MVR, I, §36, p. 259.

${ }^{35}$ SCHOPENHAUER, A. Metafisica do Belo, cap.6, p. 74. 
A melancolia predomina, porque o adverso e o inconveniente sobrepujam o favorável e o desejado. Uma representação vivaz logo reprime a outra: a mudança de humor é surpreendentemente rápida; salta-se de um extremo a outro; mostra-se, portanto, um fenômeno que se aproxima da loucura, como Goethe o descreve em Tasso e como em todos os tempos se percebeu no gênio. A isso também pertence a inclinação para monólogos, contra os quais deve-se estar em guarda, caso contrário a presença do outro é esquecida também no diálogo e se devém, por transição do monólogo, traidor de si mesmo ${ }^{36}$.

O monólogo é também outra característica marcante do gênio, visto que ele está imerso tão somente no que está sendo discutido e acaba por esquecer a pessoa com quem dialoga $\mathrm{a}^{37}$. Afora as falhas do indivíduo genial e os sofrimentos vivenciados por ele expostos aqui, este também transita facilmente para a loucura, o que pode ser visto nas biografias de vários gênios. Segundo Schopenhauer, em vários manicômios encontram-se pessoas talentosas, nas quais a genialidade olhava através da sua loucura, porém, dominada por esta ${ }^{38}$. No entanto, nem todo louco é gênio; os gênios são raríssimos e entre os gênios devem se contar apenas aqueles que produziram obras de valor permanente e indelével para a humanidade ${ }^{39}$, embora estas obras tenham sido incompreendidas pelos seus contemporâneos, situação bastante recorrente.

Defendemos que essas falhas de caráter ${ }^{40}$ do gênio (tão belamente descritas pelo filósofo), sua oscilação entre o estado onírico e a excitação nervosa ocasionada pelas duas orientações do excedente da faculdade de conhecimento e, mesmo as falhas e os méritos que não aparecem durante toda a vida, mas que não desaparecem por completo mesmo quando esse homem não se encontra em atividade genial, conduzem-no a um drama existencial. Esse drama, ou conflito existencial, consiste no fato de que o referido excedente da faculdade de conhecimento, ao mesmo tempo em que lhe proporciona o bônus de acessar a Ideia, livrando-o momentaneamente do sofrimento, torna-se seu algoz, quando retoma a orientação subjetiva do espírito, pois justamente aquilo que o eleva acima do comum faz com que ele sofra também acima do comum. Em acordo com isso, Schopenhauer afirma (...) "é preciso ainda considerar que os

\footnotetext{
${ }^{36}$ SCHOPENHAUER, A. Metafísica do Belo, cap. 6, p. 75.

${ }^{37}$ SCHOPENHAUER, A. Metafísica do Belo, cap. 6, p. 75.

${ }^{38}$ SCHOPENHAUER, A. WWV I/MVR, I, §36, p. 261.

${ }^{39}$ SCHOPENHAUER, A. WWV I/MVR, I, §36, p. 261.

${ }^{40}$ SCHOPENHAUER, A. Metafísica do Belo, cap. 6, p. 62. 
grandes dons espirituais, em consequência da atividade nervosa predominante, produzem uma sensibilidade exagerada para a dor, sob todas as formas". ${ }^{41} \mathrm{E}$, em seguida, diz que "o mais limitado de espírito é, no fundo, o mais feliz, embora ninguém consiga invejá-lo por tal felicidade" ${ }^{42}$. Recorreremos agora à obra poética Torquato Tasso do Goethe, pois esta expressa inúmeras características do gênio schopenhaueriano.

\section{Análise do drama}

Nosso interesse por essa obra justifica-se pelo fato de ela ter sido citada por Schopenhauer como uma descrição incomparável das falhas e do sofrimento do gênio ${ }^{43}$, na qual Goethe narra as alegrias e agruras do poeta Tasso, e sua busca ensandecida para atingir a perfeição expressiva na sua principal obra. Bem como sua enorme dificuldade em lidar com os homens comuns à sua volta, o que o conduz ao desvario e ao exílio. Essa peça tem como base a biografia do poeta Tasso, que foi um dos maiores poetas do renascimento e um dos poetas mais lidos na Europa até o século XIX. Sua obra prima, o poema épico Jerusalém Libertada (Gerusalemme liberata), conta a história da batalha entre cristãos e mulçumanos da primeira cruzada. O poeta Marco Lucchesi afirmara que “dentre os altíssimos vértices da poesia italiana, a Jerusalém Libertada é dos mais altos, e belos, e fascinantes, e profundos, que a literatura ocidental já produziu". ${ }^{44}$ Tão importante ao ponto de Alexei Bueno afirmar que "em Camões e em Tasso, portanto, materializam-se os dois grandes poemas modernos". ${ }^{45}$ Com isso podemos perceber o quão importante foi o poeta Tasso histórico e como este produziu uma obra genial. Seguindo o pensamento de Schopenhauer, Tasso, ao ter criado um poema épico, seria

\footnotetext{
${ }^{41}$ SCHOPENHAUER, A. Aforismos para a sabedoria de vida, cap. II, p. 44.

${ }^{42}$ SCHOPENHAUER, A. Aforismos para a sabedoria de vida, cap. II, p. 45.

${ }^{43}$ SCHOPENHAUER, A. Metafísica do Belo, cap.6, p. 62.

${ }^{44}$ LUCCHESI, Marco. In: TORQUATO, Tasso. Jerusalém Libertada. Trad. José Ramos Coelho. Rio de Janeiro: Topbooks, 1998, p. 11.

${ }^{45}$ Encontra-se no ensaio que Alexei Bueno tece comparações entre Os Lusíadas de Camões e a Jerusalém Libertada de Tasso. Cf. BUENO, Alexei. A Jerusalém Libertada e a Língua Portuguesa. In: TORQUATO, Tasso. Jerusalém Libertada. Trad. José Ramos Coelho. Rio de Janeiro: Topbooks, 1998, p. 21.
} 
gênio no grau mais elevado, pois produziu uma obra de arte cujo objeto era o homem ${ }^{46}$. Em sua autobiografia, Goethe menciona ter lido os versos desse poema desde pequeno a ponto de decorá-los e recitá-los para divertir os convidados. Segundo ele, esse poema na tradução de Kopp era um dos livros que lera com ardor desde a infância. ${ }^{47}$

Torquato Tasso nasceu em Sorrento, a 11 de março de 1544, era filho do poeta Bernardo Tasso e de Porzia de’ Rossi. ${ }^{48}$ Tasso frequentou o colégio Jesuíta e desde cedo estudou e viajou consideravelmente. Em 1556 morre a mãe de Tasso sob fortes suspeitas de envenenamento que teria sido provocado por conta de interesses no seu dote. Fato que abalou Tasso profundamente. Em 1588, ainda abalado com o ocorrido, Tasso escreve a Frei Fabiano: "minha mãe, cuja memória me será sempre cara, sempre honrada, mas sempre dolorosa e razão de nova melancolia". ${ }^{49}$ O que nos leva a crer que mesmo antes de 88, Tasso já esboçava traços de melancolia, traços que se estenderam durante toda a sua vida. Em 1561, Tasso deixa o curso de direito em Pádua para se dedicar aos estudos de filosofia e eloquência, tendo sido influenciado pela Poética de Aristóteles desde essa época. Durante sua trajetória, escreveu rimas de amor para certa dama, compôs várias obras (Rinaldo, sonetos fúnebres, Godoffredo etc) e viveu de favor em cortes. Ficou conhecido pelo comportamento arredio, melancólico e solitário. Em 1575, se apresenta por espontânea vontade à Inquisição, sendo absolvido por ela. Em $1579^{50}$, tendo transitado da genialidade para a loucura, Tasso ataca o duque Afonso e toda a corte de Ferrara, tendo sido, por esse motivo, internado no hospital de loucos e lá permaneceu durante alguns anos. Em 1595, volta a adoecer e já pressente seu próprio fim; sendo assim, morre no mesmo ano e é enterrado como indigente. ${ }^{51}$ Alguns anos mais tarde, Voltaire escreve um ensaio analisando a principal obra de Tasso. Goldini

\footnotetext{
${ }^{46}$ Segundo Schopenhauer, "só é grande gênio quem obtém sucesso com a obra de arte cujo objeto é o homem, ou seja, a pintura histórica, a escultura, a tragédia, a poesia épica”. Cf. SCHOPENHAUER, A. Metafísica do Belo, cap. 6, p. 69.

${ }^{47}$ GOETHE, Johann Wolfgang von. Memórias: Poesia e verdade. Vol I. Trad. Leonel Vallandro. Porto Alegre: Editora Globo, 1971. p. 62.

${ }^{48}$ Cronologia. In: TORQUATO, Tasso. Jerusalém Libertada. Trad. José Ramos Coelho. Rio de Janeiro: Topbooks, 1998, p. 95.

${ }^{49}$ Cronologia. In: TORQUATO, Tasso. Jerusalém Libertada. Trad. José Ramos Coelho. Rio de Janeiro: Topbooks, 1998, p. 95.

${ }^{50}$ Cronologia. In: TORQUATO, Tasso. Jerusalém Libertada. Trad. José Ramos Coelho. Rio de Janeiro: Topbooks, 1998, p. 101.

${ }^{51}$ Cronologia. In: TORQUATO, Tasso. Jerusalém Libertada. Trad. José Ramos Coelho. Rio de Janeiro: Topbooks, 1998, p. 106.
} 
escreve uma comédia intitulada Torquato Tasso e bem mais tarde Tasso é homenageado por Lord Byron em um poema intitulado The lament of Toquato Tasso ${ }^{52}$. Portanto, Tasso, além de ter sido um exemplo real daquilo que Schopenhauer entende como gênio, também ilumina o drama goethiano como personagem que reluz os conflitos do gênio e traz nome e força a esse artigo. Goethe, após viajar para a Itália e passar por um processo de entendimento da sua poesia e de si mesmo, inspira-se em uma das biografias de Tasso e, em 1789, termina de escrever o drama, escrevendo a Herder sobre a intensa dedicação com que trabalhou nessa obra ${ }^{53}$. Sendo assim, nossa análise se concentrará apenas nessa obra de Goethe.

Torquato Tasso é composto por cinco atos, seguindo o modelo da poesia dramática. O lugar da ação é Belriguardo, um palácio de veraneio. As personagens que compõem o drama são: Afonso II, duque de Ferrara; Leonor D’Este, irmã do duque; Leonor Sanvitale, condessa de Scandiano e dama de companhia da princesa Leonor; Toquato Tasso, o poeta, e Antonio Montecatino, secretário de Estado ${ }^{54}$. Ao longo do drama, Goethe evidencia a dificuldade de Tasso na lida com as pessoas da corte e como essas pessoas compreendiam superficialmente o Tasso e seu espírito poético. Afonso se mostra gentil com Tasso e o sustenta na corte, mas anseia por uma obra prima escrita por Tasso, visto que naquela época era importante para uma corte ter um poeta renomado. A princesa e sua dama de companhia admiram Tasso por ser um poeta, mas, por vezes, estranham seu comportamento solitário e arredio. A princesa desperta paixões em Tasso e, embora se mostre compreensiva para com ele, evita o romance, talvez por não compartilhar dos mesmos sentimentos dele e também por uma preocupação com as convenções sociais. A dama de companhia deseja ser a musa de Tasso, pois assim se imortalizaria através dos versos do poeta. Antonio, o homem de negócios da corte, extremamente racional e equilibrado, não tolera o comportamento de Tasso e o fato de este ser mantido na corte e sustentado pelo duque; além disso, ele se sente atingido pelo fato de Tasso, por ser poeta, despertar interesse nas mulheres da

\footnotetext{
${ }^{52}$ Cronologia. In: TORQUATO, Tasso. Jerusalém Libertada. Trad. José Ramos Coelho. Rio de Janeiro: Topbooks, 1998, p. 106.

${ }^{53}$ MOLDER, Maria Filomena. Introdução. In: GOETHE, Johann Wolfgang von. Torquato Tasso. Um drama. Trad. João Barrento. Lisboa: Relógio D’Água Editores, 1999, p. 7.

${ }^{54}$ GOETHE, Johann Wolfgang von. Torquato Tasso. Trad. João Barrento. Lisboa: Relógio D’Água Editores, 1999.
} 
corte, enquanto ele mesmo não produz versos, não sendo, portanto, aclamado por elas. Com isso, ao longo da história Antonio e Tasso se desentendem inúmeras vezes, a ponto do duque de Ferrara mandar Tasso para um exílio temporário. Sendo assim, Goethe retrata o jogo de interesse e a dissimulação por parte de uns e a falta de traquejo do poeta para lidar com tudo isso. De um lado, encontra-se a sociedade cortesã e todo o seu jogo político-social e, de outro, o poeta que preza pela sua liberdade e pela criação de uma obra de arte autêntica. Diz Tasso: "Deixa o poema falar, estância por estância! / O que me propus fazer é louvável, / mas não é tudo, ainda não cheguei lá. / Não me poupei a esforço nem trabalho. / O curso sereno de belos dias, / as horas de silêncio noite adentro, / a esta pia obra dediquei." (Goethe, 1999: 130).

Tendo em vista esse resumo do drama e a teoria do gênio de Schopenhauer, podemos apontar algumas características do gênio no Tasso e as características do homem comum no Antonio.

TASSO - "Se houvesse um tribunal universal / composto de homens bons que decidisse / o que convém, em vez de cada um / pensar que o que convém é o que lhe serve! / Não vês como aos poderosos, aos espertos, / tudo se ajusta, e eles tudo podem?"(Goethe, 1999: 65).

Nessa fala de Tasso, podemos reconhecer a teoria de Schopenhauer de que os homens comuns agem sempre guiados pelos seus interesses egoísticos, como ele esclarece no parágrafo $\S 36$ de MVR: “o homem comum, esse produto de fábrica da natureza, que ela produz aos milhares todos os dias, é, como dito, completamente incapaz de deter-se numa consideração plenamente desinteressada" ${ }^{\text {"5 }}$. Também fica claro o fato do gênio poder ser facilmente enganado pelos mais astutos, como o filósofo descreve tão bem na Metafísica do belo ${ }^{56}$. Tasso vivia cercado pelos jogos de interesse e pelo pretenso discurso racional que tenta apontar com o dedo sujo as falhas do artista. No próximo trecho, podemos apreender a busca do gênio pela essência das coisas e a necessidade de produzir uma obra com aquilo que apreendeu.

\footnotetext{
${ }^{55}$ SCHOPENHAUER, A. WWV I/MVR I, § 36, p. 256.

${ }^{56}$ SCHOPENHAUER, A. Metafísica do Belo, cap. 6, p. 81. 
TASSO - "Este ímpeto que dia e noite sinto / varrer-me o peito, em vão tento travá-lo. / Se não posso pensar nem fazer versos, / não é vida para mim a minha vida. / Tenta impedir o bicho de fiar / sua seda, nesse fiar para a morte.” (Goethe, 1999: 147.)

$\mathrm{Na}$ frase a seguir, podemos perceber que o gênio vai rapidamente de um extremo a outro, como diz Schopenhauer ${ }^{57}$.

ANTONIO - "Ouço-te, Tasso, e pasmo, inda que saiba / como o teu espírito salta facilmente, / e sem pensar, de um extremo para o outro. / Cai em ti, e controla esse furor!" (Goethe, 1999: 157). Temos aqui Antonio, secretário de estado, que lida todo o tempo com o conhecimento racional, abstrato, está preso ao seu trabalho e às relações sociais e condena o comportamento oscilante de Tasso. Em outro momento, Antonio ignora também o modo de conhecimento genial e vê Tasso como um parasita, um à-toa. Para Antonio, o gênio não tem nenhuma importância, pois não produz nada de útil. $\mathrm{O}$ próprio Schopenhauer elogia o contraste entre Antonio e Tasso feito por Goethe ${ }^{58}$ e esclarece que "o trabalho do gênio na música, filosofia, pintura ou poesia não visa utilidade ou lucro. Pois ser inútil é uma das características das obras de gênio: é também o seu título de nobreza". ${ }^{59}$ Dado que certamente não ocorre a Antonio, pois este não passa de um homem prático.

ANTONIO - "Confesso apenas o seguinte, quando um homem honrado/ retorna do trabalho árduo com a cabeça quente/ e tarde da noite pensa em repousar/ para se preparar para novas tarefas sob a sombra tão ansiada / e encontra então o espaço sob a sombra todo ocupado por um indivíduo à-toa,/ será que ele não pode acalentar no peito sentimentos humanos?" (Goethe, 1998: 127).

Em uma das falas de Tasso, no segundo ato, podemos observar a melancolia e a tendência à solidão, inerentes ao gênio, citadas por Schopenhauer ${ }^{60}$.

TASSO - "Incertos, meus passos seguem os teus, / ó princesa, e pensamentos sem norte / nem medida se agitam na minh'alma. / Parece que me acena a solidão."

\footnotetext{
${ }^{57}$ Idem, p. 79.

${ }^{58}$ SCHOPENHAUER, A. WWV II /MVR II, cap. XXXI, p. 46.

${ }^{59}$ SCHOPENHAUER, A. WWV II /MVR II, cap. XXXI, p. 47.

${ }^{60}$ SCHOPENHAUER, A. Metafísica do Belo, cap.6, p. 75.
} 
(Goethe, 1999: 56). E, por fim, na fala de Tasso, Goethe traz à luz a questão do dom e da inspiração do gênio ${ }^{61}$ e da superação ou modo diferente de lidar com a dor.

TASSO - "A lágrima que a natureza nos deu, / o grito da dor, se um homem por fï / mais não pode... E a mim, mais que a ninguém, / me deu ela, na dor, voz, melodia, / pra chorar este abismo de tristeza; / e se o homem comum na dor se cala, / um deus deu-me o dom de cantar a minha." (Goethe, 1999: 160).

\section{Considerações finais}

A partir do que foi exposto, podemos afirmar que o gênio vive sim um drama existencial que ocorre devido a oscilação das duas orientações tomadas pelo excedente da faculdade de conhecimento; além disso, podemos perceber também como a peça de Goethe expressa, significativamente, a teoria do gênio presente na filosofia de Schopenhauer, pois, além de levar em conta as características do gênio apontadas pelo filósofo, tais como pensamento contínuo na mesma coisa, visão das coisas em luz sombria e desfavorável, reflexão e pensamentos constantes, ver em toda parte o extremo etc. ${ }^{62}$ Também leva em conta a sua capacidade extraordinária de elevar-se acima do comum, bem como o dom de produzir a obra de arte. Esse drama não se restringe apenas aos poetas da modernidade. Pode-se perceber, através dos versos de Torquato Tasso, os conflitos dos gênios de qualquer época. Através desse artigo, tentamos expor, as características do gênio na filosofia de Schopenhauer, a partir da análise da obra Torquato Tasso de Goethe. Drama que retrata belamente a vida de um poeta que criou, amou, sofreu e morreu, como muitos, tragicamente. O drama daqueles que tem a alma acalentada pelo extraordinário poder de elevação estética, no entanto, é também a história dos inconformados, dos errantes que, tomados pelas sombras, cruzaram a linha entre genialidade e loucura sem fazer o caminho de volta. Drama que talvez seja um desatar de nó na garganta do próprio Goethe, um poeta mais comportado, porém igualmente genial. É como está escrito no prefácio de Tasso: "Goethe foi poeta in

\footnotetext{
${ }^{61}$ Schopenhauer diz que o nome gênio já expressa que um ser supra-humano, um genius, que em certos momentos toma posse desse indivíduo que é vantajosamente dotado. Cf. SCHOPENHAUER, A. Metafísica do Belo, cap.6, p.72.

${ }^{62}$ SCHOPENHAUER, A. Metafísica do Belo, cap.6, p. 81.

$O$ drama do gênio na metafísica do belo de Schopenhauer 
servitù, a matéria viva de Tasso, também como ele perseguido por um desejo irrefreado de infinito, por querer ser tudo, atraído pelo caos, e mergulhado vezes sem conta na sua floresta sombria" ${ }^{\prime 63}$. O próprio Goethe parece, em certo sentido, ter sido vítima da incompreensão dos seus contemporâneos. Quando inquirido por Eckermann sobre a ideia que desejara expressar em sua peça, Goethe responde: “Que ideia? Por Deus, não sei. Eu tinha a vida de Tasso, e tinha minha própria vida. Fiz de tudo a partir dos traços dessas estranhas figuras, e aos poucos vi surgir em mim a imagem de Tasso.”64

\section{Referências Bibliográficas}

BARBOZA, Jair. Apresentação. In: SCHOPENHAUER, A. Metafísica do Belo. Trad. Jair Barboza. São Paulo: UNESP, 2003.

BUENO, Alexei. A Jerusalém Libertada e a Língua Portuguesa. In: TORQUATO, Tasso. Jerusalém Libertada. Trad. José Ramos Coelho. Rio de Janeiro: Topbooks, 1998.

CHEVITARESE, Leandro. .A ética em Schopenhauer: que "liberdade nos resta" para a prática de vida? Tese de Doutorado. Pontifícia Universidade Católica do Rio de Janeiro, Rio de Janeiro, 2005.

GOETHE, Johann Wolfgang Von. Torquato Tasso. Trad. João Barrento. Lisboa: Relógio D’ Água, 1999.

Memórias: poesia e verdade. Vol I. Trad. Leonel Vallandro. Porto Alegre: Editora Globo, 1971.

Italienische Reise. Vol. 11/Hamburger Ausgabe. Munique: DTV, 1998.

KANT, Immanuel. Crítica da Faculdade do Juízo. Rio de Janeiro: Forense Universitária, 2010.

LUCCHESI, Marco. Introdução. In: TORQUATO, Tasso. Jerusalém Libertada. Trad. José Ramos Coelho. Rio de Janeiro: Topbooks, 1998.

MOLDER, Maria Filomena. Introdução. In: GOETHE, Johann Wolfgang von. Torquato Tasso. Um drama. Trad. João Barrento. Lisboa: Relógio d'água Editores, 1999.

\footnotetext{
${ }^{63}$ MOLDER, Maria Filomena. Introdução. In: GOETHE, Johann Wolfgang von. Torquato Tasso. Um drama. Trad. João Barrento. Lisboa: Relógio D’Água Editores, 1999, p. 9.

${ }^{64}$ GOETHE, Johann Wolfgang von. Italienische Reise. Vol. 11/Hamburger Ausgabe. Munique: DTV, 1998, p. 504.
} 
ROSSET, Clément. Écrits sur Schopenhauer. Paris: Presses Universitaires de France, 2001.

SAFRANSKI, Rüdiger. Schopenhauer e os anos mais selvagens da filosofia. Trad. William Lagos. São Paulo: Geração Editorial, 2011.

SCHOPENHAUER, A. Die Welt als Wille und Vorstellung. Sämtliche Werke. Textkritisch bearbeitet und herausgegeben von Wolfgang Frhr. von Löhneysen. Frankfurt am Main: Suhrkamp, 1986.

O mundo como vontade e como representação. Tomo I. Trad. Jair Barboza. São Paulo: UNESP, 2005.

O mundo como vontade e representação. Tomo II. Trad. Eduardo Ribeiro da Fonseca. Curitiba: Ed. UFPR, 2014.

Metafísica do Belo. Trad. Jair Barboza. São Paulo: UNESP, 2003.

Fontes, 2009.

Aforismos para a sabedoria de vida. Trad. Jair Barboza. São Paulo: Martins

TORQUATO, Tasso. Jerusalém Libertada. Trad. José Ramos Coelho. Rio de Janeiro: Topbooks, 1998.

Recebido: 22/12/14

Received: $12 / 22 / 14$

Aprovado: 20/02/15

Approved: 02/20/15 